\title{
Ciclo reprodutivo de machos de Liolaemus occipitalis Boulenger (Sauria, Tropiduridae)
}

\author{
Laura Verrastro ${ }^{1}$ \\ Lígia Krause $^{1}$
}

\begin{abstract}
Reproductive cycle of the male of Liolaemus occipitalis Boulenger (Sauria, Tropiduridae). The aim of this work is to describe the reprodutive cycle of the males of $L$. occipitalis from the coastal sand-dunes of Rio Grande do Sul State, Brazil. It was carried out between April/86 and March/88, at Jardim Atlântico Beach, Tramandaí, Rio Grande do Sul. These lizards showed reprodutive activity between September and December, with a retreat period during January and February. The seasonality of the reprodutive cycle became fully evident by the monthly variation of the testicular mass, showing an inverse relation with the temperature along the year. KEY WORDS. Tropiduridae, Liolaemus, Neotropical lizards, reproductive cycle
\end{abstract}

Um importante indicador da biologia reprodutiva de uma espécie é a determinação de seu ciclo reprodutivo. Em zonas tropicais, a precipitação tem sido o principal fator que influencia o ciclo reprodutivo das espécies de lagartos (LICHT \& GORDMAN 1970; SEXTON et al. 1971). A sazonalidade na reprodução de répteis ovíparos é comum em espécies de zonas temperadas (FITCH 1980), onde as grandes variações de temperatura e fotoperíodo, ao longo do ano, podem determinar um recesso reprodutivo (LICHT 1966; LICHT \& GORDMAN 1970).

Os pequenos lagartos do gênero Liolaemus Wiegmann, 1834 são amplamente distribuídos na América do Sul, sendo conhecidas aproximadamente 120 espécies (CEI 1986). No Brasil, este gênero está representado por três espécies: Liolaemus lutzae Mertens, 1938; L. wiegmannii (Duméril et Bibron, 1837) (em revisão pela primeira autora) e L. occipitalis Boulenger, 1885. Esta última espécie habita as dunas costeiras dos estados do Rio Grande do Sul e de Santa Catarina, caracterizando-se por apresentar comprimento rostro-anal médio nos machos adultos de 60,2 $\mathrm{mm}$, padrão críptico de coloração, alimentação basicamente insetívora e pelo recesso da sua atividade nos períodos frios do ano (VERRASTRO \& KRAUSE 1994).

Este trabalho tem como objetivo verificar o ciclo reprodutivo nos machos de L. occipitalis, numa população das dunas do Rio Grande do Sul.

1) Departamento de Zoologia, Instituto de Biociências, Universidade Federal do Rio Grande do Sul. Avenida Paulo Gama, prédio 12105, 90046-900 Porto Alegre, Rio Grande do Sul, Brasil. 


\section{MATERIAL E MÉTODOS}

A área de estudo localiza-se na praia Jardim Atlântico, Município de Tramandaí, a cerca de $200 \mathrm{~m}$ a oeste da rodovia RS-786 ( $30^{\circ} 40^{\prime} \mathrm{S}$ e $\left.50^{\circ} 10^{\prime} \mathrm{W}\right)$. O solo é basicamente arenoso, com montículos de areia, sendo apenas 7 a $9 \%$ do terreno coberto por vegetação herbácea, cuja composição depende, em grande parte, da proximidade maior ou menor com o lençol freático (VON PFADENHAUER \& RAMOS 1979; vON Pfadenhauer 1980; WAechter 1985, 1990).

Nas áreas de montículos baixos $(20-50 \mathrm{~cm})$, entre as espécies mais representativas podem ser citadas Panicum racemosum Spreng e Spartina ciliata Kunth; e em áreas planas mais úmidas são abundantes espécies como Imperata sp., Juncus maritimus Lam. e Lycopodium alopecuroides Linnaeus.

Os dados climáticos de temperatura e precipitação foram obtidos da estação meteorológica DEPREC/RS (Departamento de Portos, Rios e Canais do Rio Grande do Sul), no município de Imbé, localizado a $10 \mathrm{~km}$ ao norte do local de estudo.

O clima é do tipo "Cfa", subtropical úmido com verões quentes (segundo o sistema Köppen). A precipitação média anual é de 1323 mm, não ocorrendo estação seca característica (Fig. 1). A temperatura média anual é de $20^{\circ} \mathrm{C}$, com extremos absolutos entre $2,2^{\circ} \mathrm{C}$ e $38,5^{\circ} \mathrm{C}$. A média das mínimas é de $12,2^{\circ} \mathrm{C}$, em junho e julho, sendo de $21,3^{\circ} \mathrm{C}$ em fevereiro, enquanto que a das máximas é de $27,6^{\circ} \mathrm{C}$, no verão, e de $18,3^{\circ} \mathrm{C}$, no inverno (HASENACK \& FERRARo 1989).

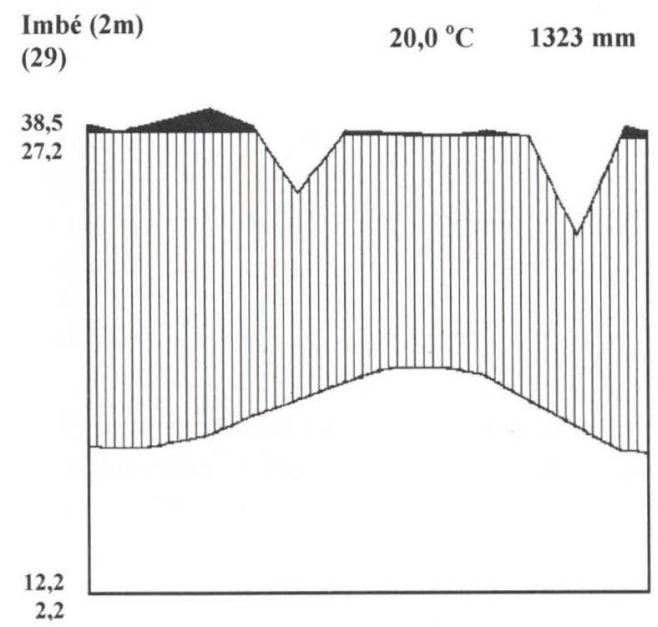

Fig. 1. Diagrama climático, segundo Walter, 1986 para Imbé-Tramandai, Rio Grande do Sul, 2907'W, 02m. Extraído de HASENACK \& FERRARO 1989.

A captura dos indivíduos foi realizada mensalmente, entre abril/1986 e março/1988 (com exceção do mês de julho, quando não foi possível realizar coletas). As coletas foram realizadas manualmente, entre 10:30 h e 14:30 h, obtendo-se um total de 70 exemplares.

Em laboratório, os animais foram dissecados sob lupa, sendo retirados os testículos e epidídimos direitos para montagem de lâminas histológicas. Foram 
selecionados indivíduos com comprimento rostro-anal (CRA) entre $40 \mathrm{~mm}$ e $60 \mathrm{~mm}$ para análise histológica comparativa, a fìm de verificar diferenças anatômicas que identifiquem a transição à maturação sexual.

A determinação da atividade gonadal ao longo do ano foi calculada através da análise do volume testicular, utilizando-se a fórmula proposta por MAYHEW (1963). Para esta análise, utilizou-se os indivíduos coletados entre março/87 e fevereiro/88. A atividade testicular mensal foi expressa pela razão entre o comprimento rostro-anal do animal e o volume dos testículos e testada através da análise de variância (ANOVA). Os dados climáticos foram correlacionados estatisticamente com a atividade testicular, através do teste de Pearson (ZAR 1984).

\section{RESULTADOS E DISCUSSÃO}

Os resultados demonstraram que os indivíduos de L. occipitalis menores de $50,0 \mathrm{~mm}$ (CRA) não apresentaram indícios de atividade gonadal na época reprodutiva, mas a partir deste comprimento, foi verificada a ocorrência de espermatozóides tanto na luz dos túbulos seminíferos, como na luz do epidídimo. Desta forma determinou-se que os machos de L. occipitalis atingiram sua maturação sexual a partir dos 50,0 mm. VERRASTRO \& KRAUSE (1994) verificaram ainda, que os indivíduos de L. occipitalis estavam sexualmente maduros na primeira estação reprodutiva após o nascimento. Comparativamente, RoCHA (1992) encontrou machos de L. lutzae maduros sexualmente, antes do primeiro ano de vida e, com tamanho mínimo de $61,1 \mathrm{~mm}$.

A análise histológica das gônadas demonstrou que em machos sexualmente maduros existiu atividade gonadal entre setembro e janeiro, com espermatozóides nos túbulos seminíferos e epidídimo. Entre janeiro e fevereiro, os machos não apresentaram indícios de atividade celular. Entre março e agosto, observou-se atividade espermatogênica, sendo que a formação e liberação final dos espermatozóides somente ocorreu na primavera.

O volume testicular variou significativamente nos meses de estudo $\left(\mathrm{F}_{20,32}\right.$ $=4,59 ; \mathrm{p}=0,0016)$, sendo máximo em outubro, reduzindo-se em novembro e alcançando o mínimo em fevereiro. A atividade testicular estava correlacionada significativamente com a temperatura $(r=-0,75 ; p<0,01)$, onde verificou-se uma relação inversa. Durante o outono e o inverno a gônada cresce no processo espermatogênico, diminui de tamanho na época de atividade reprodutiva, chegando a seu tamanho mínimo após o período de acasalamento (Fig. 2).

Machos de $L$. occipitalis apresentaram período reprodutivo entre setembro e dezembro, caracterizando-se por um ciclo não-contínuo, claramente sazonal, como descrito por LICHT \& GORDMAN (1970). Este padrão foi encontrado na maioria dos lagartos de zonas temperadas (FITCH 1970).

Trabalhos realizados por LiCHT (1966) e LiCHT \& GORDMAN (1970) postularam que a temperatura e o fotoperíodo influenciam a atividade reprodutiva. O ciclo reprodutivo em lagartos de regiões tropicais geralmente está correlacionado com a variação da precipitação ao longo do ano, como verificado por RoCHA (1992) em L. lutzae. Por outro lado, em lagartos de zonas temperadas, onde pode existir um 
período de hibernação, a variação da temperatura é um fator determinante do ciclo reprodutivo (FITCH 1970). PINILLA (1991) encontrou, em L. wiegmannii na Argentina, um sincronismo entre o ciclo reprodutivo e a temperatura.

O Estado do Rio Grande do Sul apresenta estações bem definidas, determinadas pela variação da temperatura, como foi especificado anteriormente em material e métodos. A correlação significativa entre o ciclo gonadal e a temperatura verificada em machos de $L$. occipitalis sugere que a temperatura é um importante fator na determinação da sazonalidade existente na reprodução deste lagarto.

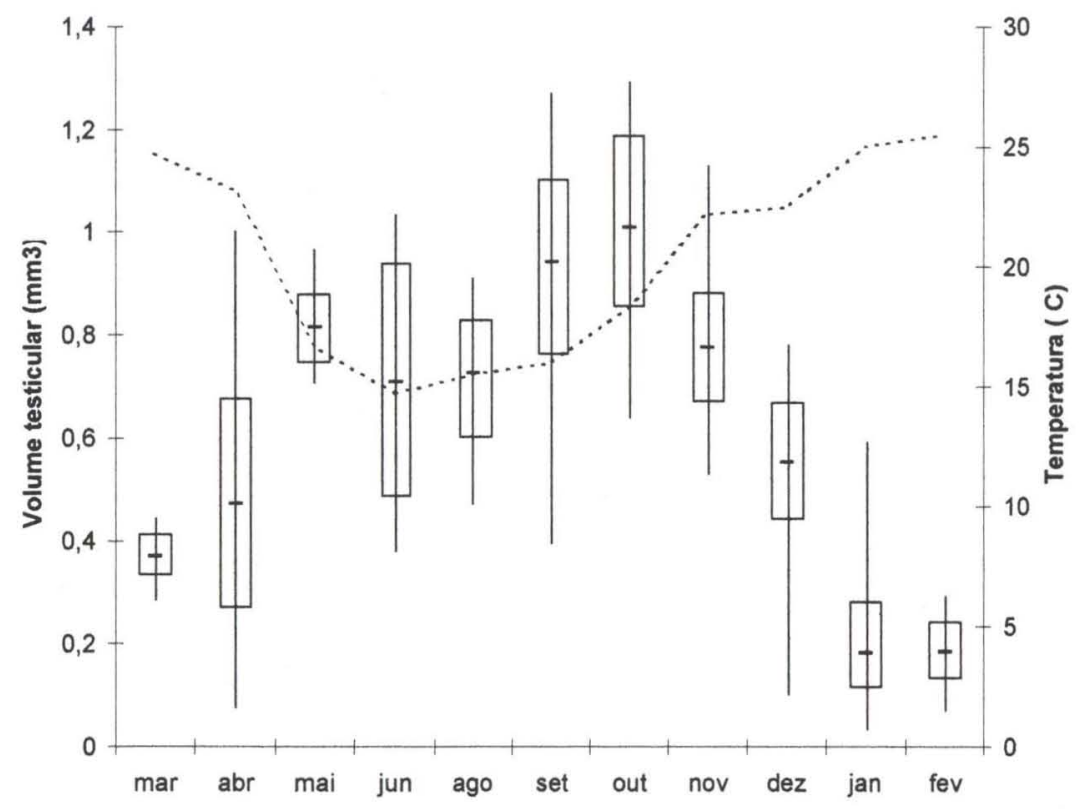

Fig. 2. Variação anual do volume testicular em Liolaemus occipitalis, na praia Jardim Atlântico/Tramandai, Rio Grande do Sul. Estão representados os valores médios (linha horizontal), máxima, mínima (linha vertical), desvio padrão(barra), e a relação com a variação anual da temperatura $(r=-0,75, p<0,01)$.

\section{CONCLUSÃO}

Os machos de L. occipitalis possuem um padrão de reprodução sazonal nas dunas costeiras do Estado do Rio Grande do Sul, apresentando período reprodutivo entre setembro e dezembro. $\mathrm{O}$ ciclo reprodutivo está fortemente relacionado com a variação anual da temperatura.

AGRADECIMENTOS. Este trabalho faz parte da Dissertação de Mestrado da primeira autora. Foi subvencionado através de Bolsa de Demanda Social CAPES (86-89) e Auxílio de Pesquisa CNPq (No. 000408825/87). Agradecemos o auxilio da Profa. Sonia M. Lauer de Garcia pelo acesso ao laboratório de Histologia do Departamento de Ciências Morfológicas desta Univer- 
sidade, e pela orientação na interpretação dos cortes histológicos; assim como a Dra. Cláudia Keller pela ajuda no trabalho de laboratório, e ao Biól. Clóvis Bujes pela auxílio na elaboração dos gráficos e a valiosa correção do manuscrito.

\section{REFERÊNCIAS BIBLIOGRÁFICAS}

CEI, J.M. 1986. Reptiles del centro, centro-oeste y sur de La Argentina. Torino, Museo regionale di Scienze Naturali Torino, Monografie IV, 527p.

FICHT, H.S. 1970. Reproductive cycles in lizards and snakes. Misc. Publ. Univ. Kans. Mus. Nat. Hist. 52: 1-247.

1980. Reprodutive estrategies of reptiles, p.25-31. In: J.B. MURPHY \& J.J. ColLiNS (Eds). Reproductive biology and diseases of captive reptiles. New York, SSAR Contributions in Herpetology 1, 564p.

HASENACK, H. \& W.L. FerRaRo. 1989. Considerações sobre o clima da região de Tramandaí, RS. Pesquisas, São Leopoldo, (22): 53-70.

LiCHT, P. 1966. Reproduction in lizards: influence of temperature on photoperiodism in testicular recrudescense. Science 154: 1668-1670.

Licht, P. \& G.C. GoRdMAN. 1970. Reproductive and fat body cycles in Caribbean Anolis lizards. Univ. Calif. Publ. Zool. 95: 1-52.

MAYHEW, W.W. 1963. Reproduction in the granite spiny lizard Sceloporus orcutti. Copeia 1963: 114-122.

PINILLA, M.P.R. 1991. Reproducyive and fat body cycles of the lizard Liolaemus wiegmanni. Amphibia-Reptilia, Leiden, 12: 195-202.

RocHA, C.F.D. 1992. Reproductive and fat body cycle of the tropical sand lizard (Liolaemus lutzae) of southeastern Brazil. Jour. Herpetol. 26 (1): 17-23.

SEXTON, O.J.; E.P. ORTLEB; L.M. HATHAWAy \& R.E. BALLINGER. 1971. Reproductive cycles of tree species of anoline lizards from the Isthmus of Panama. Ecology, Washington, 52: 201-215. 1971.

Verrastro, L. \& L. Krause. 1994. Analysis of growth in a population of Liolaemus occipitalis Boul. 1885, from the coastal sand-dunes of Tramandaí, RS, Brazil (Reptilia-Tropiduridae). Stud. Neotrop. Fauna Environ. 29 (2): 99-111.

VON PFADENUHAUER, J. 1980. Die vegetation der küsttendünen von Rio Grande do Sul, Südbrasilien. Phytocoenologia. 8 (3/4): 321-364.

VON PFADENUHAUER, J. \& F.R. RAMOS. 1979. Um complexo de vegetação entre dunas e pântanos próximo a Tramandaí. Rio Grande do Sul, Brasil. Iheringia, Sér. Bot., Porto Alegre, 25: 17-26.

WAECHTER, J.L. 1985. Aspectos ecológicos da vegetação de restingas no Rio Grande do Sul, Brasil. Comun. Mus. Ci. PUCRS, Sér. Bot., Porto Alegre, (33): 49-68.

1990. Comunidades vegetais das restingas do Rio Grande do Sul. In: Simpósio de Ecossistemas da Costa Sul e Sudeste brasileira, 2, Águas de Lindóia. São Paulo, ACIESP, p. 228-48.

ZAR, J.H. 1984. Bioestatistical analysis. New Jersey, Prentice-Hall Inc., Englewood Cliffs, 718p.

Recebido em 10.X.1997; aceito em 08.III.1999. 